\title{
ESCOLHA PROFISSIONAL: UMA VISÃO HUMANISTA-EXISTENCIAL
}

DOI: 10.22289/2446-922X.V4N1A1

\section{RESUMO}

\author{
Jefferson Domingues de Oliveira ${ }^{1}$
}

O artigo apresenta a escolha profissional como um momento de decisão como também de muitos conflitos, assim uma profissão faz parte de um processo de vida daqueles que desejam tornar-se um profissional. A partir desta perspectiva, este estudo objetiva refletir sobre os aspectos envolvidos na escolha profissional, a partir de um olhar fenomenológico-humanista, a partir de uma revisão teórica conceitual. Espera-se com este estudo contribuir para ampliar a compreensão sobre as variáveis que envolvem a escolha da carreira aliada à maturidade $e$ evidenciar abertura de projetos de intervenção multidisciplinar, para orientar jovens e adultos nas incertezas sobre o futuro profissional.

Palavras-chave: Escolha; Estudante; Fenomenologia; Profissão.

\section{ABSTRACT}

The article presents a professional choice as a moment of decision as well as many conflicts, as well as a profession part of a life process of those who wish to become a professional. From this perspective, this study aims to reflect on those involved in professional choice, from a phenomenological-humanist perspective, from a theoretical conceptual revision. It is hoped with this study to broaden an understanding of how variables that involve a career choice allied to maturity and evidence openness of multidisciplinary intervention projects, to guide young people and adults in the uncertainties about the professional future.

Keywords: Choice; Student; Phenomenology; Professional Occupation.

\section{INTRODUÇÃO}

O Ensino Médio no Brasil vem sendo nas últimas décadas, reconhecido e assumindo uma função importante na vida da sociedade, principalmente na vida do jovem, devido à acessibilidade no ensino ter sido oferecida, a quem antes não o tinha, tornando-se então veículo que leva para o Ensino Superior, para que assim tenha oportunidade de qualificarem e ingressarem no mercado de trabalho (Bastos, 2005).

Sendo o ensino reconhecido e dando oportunidade de aprendizado aos jovens, levaos ao momento em que precisam fazer escolhas relacionadas à vida profissional. Muitas vezes estão vivenciando o processo de adolescência, passando por crises de identidade,

\footnotetext{
${ }^{1}$ Endereço eletrônico de contato: psicologojefferson@hotmail.com

Recebido em 03/09/2017. Aprovado pelo conselho editorial para publicação em 04/12/2017.
}

Rev. Psicol Saúde e Debate. Fev., 2018:4(1):1-8. 
repleto de angústias, ansiedade, dúvidas, medos e incertezas, diante do novo mundo que está sendo descoberto e deparam-se então com cobranças e exigências, de uma postura madura, mesmo não tendo uma percepção autêntica da realidade, podendo então a sua vida inteira ser comprometida (Silva, 2011).

A escolha profissional acontece após o enceramento do ensino médio. É um momento de urgência, pois é preciso então fazer escolhas decisivas, o desenvolvimento do indivíduo já se deu a partir do convívio familiar e social. O jovem então se sente pressionado a escolher uma carreira profissional, tanto pela família e por suas relações afetivas, quanto por sua estória de vida, pela maneira que fez a sua vivência na sociedade, também por estar se deparando com os anseios e idealizações dos familiares (Luchiari, 1996).

Pensando no âmbito da escolha está baseada na hermenêutica, do ser-aí, que lançado na indeterminação da vida, percebe-se, por indeterminação originária, encontra-se lançado, idealizado, decidido ou escolhendo. Acrescentando [...] as coisas não se dão necessariamente e em sua totalidade, sob o domínio do seu querer, da sua vontade. O ser-aí é, portanto, sempre decidido, tem de ser. Logo, querer, desejar, ansiar e ter vontade são tardios, pois o mais originário consiste na indeterminação do ser-aí, tendo sempre, portanto, de decidir, de construir a sua morada, que não lhe é dada a priori[...] (Feijoo \& Magnan, 2012).

O ser humano consegue desenvolver suas habilidades vocacionais, podendo ser sua atividade profissional, na sua vida adulta, desde sua infância. O caminho vocacional inicia-se a partir das funções assumidas da demanda familiar que surge da criança para os pais e do posicionamento que eles assumem. A construção se dá desde o nascimento, tendo o círculo familiar significativa importância para a vida profissional (Magalhães, 2008).

No processo de evolução do adolescente, a futura escolha profissional resulta do intenso processo iniciado na infância e se transforma conforme a personalidade do indivíduo vai se formando (Levenfus, 2001). Diante deste argumento Rilke, posiciona a necessidade de ter calma com que não está esclarecido, a necessidade de viver as experiências de cada momento, como também estimar as interrogações. Em complemento, Silva e Mendes (2015) apontam a adolescência como uma fase de múltiplas interrogações, neste sentido percebe a Psicologia como uma ferramenta de auxilio, para autoconhecimento, para esclarecimento diante dos conflitos vivenciados.

Moreira (2007), citando Carl Rogers, aponta como centro da educação, exclusivamente, o desenvolvimento do ser humano. Percebe-se no momento em que os propósitos pessoais de cada aluno estão ligados aprendizagem. Afirma Rogers que quando propósitos e aprendizagem estão alinhados é considerado então como considerável.

Rev. Psicol Saúde e Debate. Fev., 2018:4(1):1-8. 
O adolescente vive um movimento da infância para a vida adulta que atinge o seu aspecto biopsicossocial. Sendo que, para cada indivíduo é uma vivência diferente, devido a esse movimento de mudança e passagem ser de acordo com sua realidade social. Entendendo que este ciclo de apuro e instabilidade, acontece devido ser um processo de profundas mudanças físicas e psicológicas, e se sua realidade sócio-histórico-cultural for complexa, maior sua dificuldade para o amadurecimento. Na busca de uma identidade, de uma identidade própria, o jovem adolescente, procura se afirmar nos grupos, criando vínculos afetivos, que o protegerá das suas crises existenciais. Tendo construído a sua identidade facilitará para encontrar seu caminho vocacional (Esbrogeo, 2008).

Segundo Filizatti (2002), quando o jovem está envolvido na escolha profissional, ele está passando também por mudanças corporais e psíquicas, tornando então um momento de dúvidas e conflitos, demonstrando não estar preparado para uma escolha que a priori é decisiva. O sentido da própria existência, esta ligado ao processo de escolha, como afirma Rilke (1953/1989):

[...] Ninguém o pode aconselhar ou ajudar, - ninguém. Não há senão um caminho. Procure entrar em si mesmo. Investigue o motivo que o manda escrever; examine se estende suas raízes pelos recantos mais profundos de sua alma; confesse a si mesmo: morreria, se lhe fosse vedado escrever? Isto acima de tudo: pergunte a si mesmo na hora mais tranquila de sua noite: Sou mesmo forçado a escrever?' Escave dentro de si uma resposta profunda. Se for afirmativa, se puder contestar àquela pergunta severa por um forte e simples 'sou', então construa a sua vida de acordo com esta necessidade [...] (pp.22-23).

Neste caminho, Rilke aponta que não há um caminho pronto, é uma construção vinculado a um mergulho em si mesmo. Fazendo um contraponto ao pensamento de Stein, o que a pessoa é em essência. Neste sentido, a vida não está vinculada exclusivamente a uma identidade profissional. Para que a escolha profissional tenha um efeito positivo na vida de todo ser humano, sendo possível de conquistar, é preciso então que sejam reconhecidas as limitações e as capacidades produtivas de cada indivíduo, para que assim, seja menos fantasiada ao mesmo tempo que sofrida (Weinberg, 2001).

Segundo Super (1957) apud Oliveira (2011), todo ser humano tem um ciclo vital, que pertence a estágios de carreira, correspondendo ao desenvolvimento do indivíduo. O primeiro estágio inicia-se aos quatro anos de idade, e o último encerra-se após os 65 anos. 
Interessando ter conhecimento apenas dos dois primeiros estágios, que ajudarão a compreender de maneira mais concreta, sendo estes de crescimento e exploração.

Para o referido autor citado, crescimento tendo seu início aos quatro anos de idade e encerrando aos treze, momento em que a criança consegue a priori estabelecer sua relação com o mundo, desenvolvendo suas capacidades, atitudes e interesses, devido este fato no futuro reconhecerá a importância de realizar e cumprir tarefas, facilitando assim, a sua vivência no mercado de trabalho. Sucessivamente vivenciará o estágio da exploração: este estágio refere-se dos 14 aos 24 anos, momento em que há uma descoberta de identidade, na busca de descobrir o seu lugar no mundo, através do descobrimento de si e na maneira que consegue se compreender, pela sua interação na escola e nas atividades de lazer, percebendo assim os interesses próprios, facilitando desta forma, onde no mercado de trabalho terá uma ocupação que o adeque. A partir do momento em que consegue perceber sua vocação, então estabelece um caminho que busca compreensão, treinamento e educação, que o especialize no seguimento ocupacional, acontece ocasionalmente na adolescência tardia e início da vida adulta, denominada de conversão. Caracteriza-se pela conversão da preferência especificada no efetivo engajamento com a escolha através de treinamento e educação especializada e ingresso num seguimento ocupacional (Super, 1957 apud Oliveira, 2011).

Para Freire (2009), torna-se necessário reconhecer que todo ser humano vivencia continuamente um processo de aperfeiçoamento, e acúmulo de experiências que o faz um ser único. Sendo que o ser humano interruptamente faz escolhas, "será que eu devo evitar fazer aquilo que realmente quero fazer?", "Será que eu deveria viver minha vida como os outros querem que eu viva?" (Dyer, 1976, p. 12). Assim, Sberga e Massimi (2015) discorrem que a educação é um ato de formar uma pessoa, neste caminho indicar os talentos natos e desenvolvidos como forma de perceber a vocação.

Escolher uma carreira é depositar nela sonhos, desejos e muitas vezes está envolvida a pressão da sociedade e as pessoas que estão presentes na vida do jovem, e dependendo da maneira com que o indivíduo se posiciona, a partir das dificuldades enfrentadas, a sua escolha profissional poderá não ter consequências positivas (Filizati, 2002).

Feijoo e Magnam (2012) citam este momento de escolha profissional como todos os dilemas aproximados desta vivencia, passa pelo conceito de Kierkegaard, pois acontece pela via do temor e sem tremor. Repensar na necessidade de inserir a Psicologia nas instituições de ensino, para compreensão do adolescente em como um ser humano na sua totalidade e 
no seu mundo e como se relaciona, como também no que refere as questões de aprendizagem (Moreira e Gomes, 2016).

Conjuntamente aos conflitos vivenciados neste processo de criação de identidade, este ainda precário, o adolescente passa por conflitos de gerações, pois não sabe corresponder aos próprios desejos e anseios e também não quer aceitar as verdades impostas pela família. Contrapondo-se aos desejos e expectativas de seus pais, o adolescente busca definir os seus objetivos e a si mesmo. Esse mecanismo de oposição é próprio do momento que vivencia, muitas vezes, erroneamente confundido com a ideia de que o adolescente está repudiando o sistema de valores dos pais e apresentando uma quebra no processo identificatório com os mesmos (Levenfus, 2001).

Os pais são a primeira referência que o adolescente possui. Devido ao fato de serem cada vez mais instáveis no sentido de estarem atualmente estressados por causa do trabalho e, ainda não terem aceitado o processo de transformação que viveram da juventude para a vida adulta, havendo uma supervalorização e o desejo de serem para sempre jovens, por outra parte assumem uma postura rígida, fazendo com que muitos jovens amadureçam precocemente (Dossiê Universo Jovem, 2005, p. 58).

O cenário do mercado de trabalho teve mudanças, décadas anteriores ter um diploma de graduação implicava diretamente na conquista de um emprego e estabilidade profissional. Atualmente este cenário tem sofrido modificações constantes, devido a mudanças inesperadas, são geradas dúvidas e incertezas, diante do mercado de trabalho. Isso tem feito com que pais e educadores encontrem barreiras para nortear qual o melhor caminho a seguir na proposta de escolha profissional, levando jovens a estarem cada vez mais perdidos diante da sociedade (Melo-Silva et al 2007).

O jovem que tem um preparo e conhecimento sobre o mercado de trabalho, possui maior facilidade de refletir com olhar mais racional sobre as exigências do mercado e as suas habilidades pessoais e consegue estabelecer compatibilidade entre teoria e prática, favorece a sua escolha profissional, tornando-a mais efetiva (Gondim, 2002).

Entendendo que iniciar o curso superior é simbólico para a vida do ingresso, tornase necessário ajudar jovens a terem horizontes ampliados, levando-os a orientação vocacional, para assim evitar desistências e frustrações durante sua graduação, devido à escolha do curso. Ter autoconhecimento, apoio dos familiares, junto aos educadores, maior clareza do mercado de trabalho, aumentando assim possibilidade de amadurecimento diante diversidades de escolhas que são oferecidas (Silva, 2011).

Há muitas verdades e muitos mitos em constatações tão genéricas como essas. 0 fato é que democratização e elitização são elementos presentes nas instituições públicas e 
privadas de ensino superior, tratando-se de um assunto de grande complexidade, porque envolve outros fatores além daqueles que vêm sendo apresentados e discutidos. Fato é que no processo da escolha profissional, o jovem ao sair do ensino médio é repleto de incertezas, ao mesmo tempo com ansiedades sobre seu futuro e terá que fazer a escolha profissional, independente de estar preparado ou não para tal ato, tendo muitas vezes que fazer novas opções de escolhas profissionais (Freitas, 2004; Silva, 2011).

Levando a reflexão ao processo de escolha profissional Esbrogeo (2008), pontua que existem inúmeras informações distorcidas em vários veículos de comunicação principalmente a internet, que não expõe com clareza informações sobre o curso, bem como a falta de interesse do jovem na busca de informações e também se remetendo aos anseios da família frente ao curso de escolha, associado também à falta de maturidade frente à vivência da escolha. Neste caminho Sberga \& Massimi (2015) apontam a importância da fenomenologia enquanto método, pois há investigação das vivencias, na compreensão de Edith Stein nas três instancias do ser humano biológico, psíquico e espiritual.

\section{CONCLUSÃO}

No que se refere à escolha profissional, torna-se necessária reconhecer a pessoa como ser na sua totalidade, corpo e mente, como também à presença do psicólogo nas escolas, devido ao processo de escolha estar permeado pela influência da estória de vida de cada pessoa, a partir do que introjeta suas experiências e relações sociais. Neste sentido a fenomenologia e a percepção de Edith Stein, como suporte aqueles que escolhem, pois reconhece o ser humano com um todo, reconhecendo o momento de extrema angustia, assim reconhecendo as possibilidades do vir-a-ser. Deste modo a orientação vocacional torna-se necessária como auxílio, ajudando a pré-vestibulandos a terem maior clareza e maturidade diante das escolhas e da profissão que almeja.

A escolha profissional deve ser vivenciada com maior maturidade, para que possa evitar abandono no curso e frustrações futuras, bem como a desistência do exercício da profissão.

Rev. Psicol Saúde e Debate. Fev., 2018:4(1):1-8. 


\section{REFERÊNCIAS}

Bastos, J. C. (2005). Orientação vocacional/profissional de abordagem sócio-histórica: uma proposta de concretização da orientação para o trabalho sugerida pelos parâmetros curriculares nacionais. Revista Virtú, 2, 1-7.

Dossiê Universo Jovem 3.(2005). Mtv Brasil. Disponível em: <http://www.espm.br/ >. Acesso em: 07 ago 2016.

Dyer, W.W. (1976). Seus pontos fracos.19. ed. Rio de Janeiro: Nova Era.

Esbrogeo, M. C. (2008). Avaliação da Orientação Profissional em grupo: o papel da informação no desenvolvimento da maturidade para a escolha da carreira (Doctoral dissertation, Universidade de São Paulo).

Feijoo, A. M. L. C., \& Magnan, V. C. (2012). Análise da escolha profissional: uma proposta fenomenológico-existencial. Psicologia: Ciência e Profissão, 32(2), 356-373.

Filizatti, R. (2003). O desafio da escolha profissional. Psico-USF, 8(1), 93-94.

Freitas, A. A. M. (2004). Acesso ao ensino superior: estudo de caso sobre características de alunos do ensino superior privado. Revista Inter Ação, 29(2), 261276.

Gondim, S. M. G. (2002). Perfil profissional e mercado de trabalho: relação com formação acadêmica pela perspectiva de estudantes universitários.

Levenfus, R. S. (2001). Psicodinâmica da escolha profissional. Porto Alegre: Artmed.

Soares-Luchiari, D. (1996). Os desejos familiares e a escolha profissional dos filhos. Revista de Ciências Humanas, 14(20), 81-92.

Magalhães, M. O. (2008) Relação entre ordem de nascimento e interesses vocacionais. Estudo Psicologia, Campinas, 25(2), 208-210.

Matos, M. A.. (1998). CAROLINA BORI: A Psicologia Brasileira como Missão. Psicologia USP, 9(1), 67-70.

Melo-Silva, L.L. Almeida, F. (2007). Grupo de Pais: Relato de Experiência em Grupo Operativo. In: I Congresso Latino Americano de Orientação Profissional da ABOP e VII Simpósio Brasileiro de Orientação Vocacional \& Ocupacional. Bento Gonçalves. Resumos. São Paulo.

Moreira, V. (2007). De Carl Rogres a Merlau-Ponty: a pessoa mundana em psicoterapia. São Paulo: (EDIÇÃO). Annablume. 
Moreira, I., \& Oliveira, R. (2016). A importância do trabalho do psicólogo no ambiente escolar: perspectivas da educação na atualidade. Psicologia E Saúde em Debate, 2(Ed. Esp. 1), 14-27. doi:10.22289/2446-922X.V2EEA2

Oliveira, A. A. A. D., Resstel, C. C. F. P., \& Justo, J. S. (2014). Desamparo Psíquico $\mathrm{Na}$ Contemporaneidade. Revista de Psicologia da UNESP, 13(1), 21-32.

Oliveira, R. S. (2011). Relações entre interesses ocupacionais e variáveis de carreira em estudantes de psicologia (Doctoral dissertation, Dissertação de Mestrado não publicada, Programa de Pós-Graduação em Psicologia, Universidade Federal da Bahia, Salvador, Bahia).

Rilke, R. M. (1989). Cartas a um jovem poeta. (P. Rónai, trads.). Rio de Janeiro: Globo (Trabalho original publicado em 1953).

Sberga, A. A., \& Massimi, M. (2014). A formação da pessoa em Edith Stein.

Silva, L. T. B. D. (2011). O jovem e a escolha profissional no século XXI: Apresentado pelo X Congresso Nacional de Educação- EDUCERE; Curitiba-PR, 203 -213.

Silva, T., \& Mendes, D. (2015). A contemporaneidade acerca da adolescência e a sexualidade. Psicologia E Saúde Em Debate, 1(1), 1-18. doi:10.22289/2446922X.V1N1A1

Weinberg, C. (2001). Geração Delivery: adolescer no mundo atual. São Paulo: Sá. 